\title{
ENSINO DE EMPREENDEDORISMO POR MEIO DA UTILIZAÇÃO DE METODOLOGIAS ATIVAS: ANÁLISE COMPARATIVA DA PERCEPÇÃO DOS ESTUDANTES
}

Juliana Pequeno ${ }^{1}$

Veruska Albuquerque ${ }^{2}$

Mauro Celio Araujo Dos-Reis ${ }^{2}$

Sandson Barbosa Azevedo ${ }^{3}$

${ }^{1}$ ENEG - Escola de Ensino de Negócios / UniProjeção / Faculdade Projeção

${ }^{2}$ ENEG - Escola de Ensino em Negócios / UniProjeção / Faculdade Projeção

${ }^{3}$ Centro Universitário do Distrito Federal - UDF 


\title{
ENSINO DE EMPREENDEDORISMO POR MEIO DA UTILIZAÇÃO DE METODOLOGIAS ATIVAS: ANÁLISE COMPARATIVA DA PERCEPÇÃO DOS ESTUDANTES
}

\begin{abstract}
Resumo: Tendo em vistas a importância e necessidade da disseminação de educação empreendedora nas instituições de ensino, este trabalho foi desenvolvido no sentido de realizar uma análise comparativa da percepção de estudantes de nível superior em relação à sua participação, por meio de metodologia ativa de ensino, na disciplina de empreendedorismo. No esforço para atender este objetivo, foi realizado estudo de caso com análise descritiva de dados coletados de maneira eletrônica entre os meses de junho e julho de 2017. Como resultado, foi possível notar a confirmação, neste estudo, de informações relatadas pelos alunos no estudo anterior a partir da análise comparativa no sentido de destacar a fundamental importância da utilização de métodos ativos de ensino.
\end{abstract}

Palavras-chave: Empreendedorismo. Protagonismo do Aluno. Métodos Ativos de ensino. 


\section{Introdução}

"A escola com que sonhamos é aquela que assegura a todos a formação cultural e científica para a vida pessoal, profissional e cidadã, [...]” LIBÂNEO (1998).

Notadamente a evolução humana passa pela evolução do trabalho, pelo jeito que este transforma a natureza a sua volta, na tentativa de inserir qualidade ao meio em que vive. Esta evolução quase se materializa no uso de metodologias, ferramentas e recursos tecnológicos bem como nas condições que cercam as inúmeras carreiras profissionais. Uma vez que tudo evolui em função do provimento das condições em que o homem precisa para viver melhor, para facilitar sua forma de produção e também nas condições em que ele realiza este trabalho.

Um contexto no qual a Educação acaba por, mais do que nunca, se preocupar cotidianamente, porém apenas, com a formação completa dos indivíduos - competências em vários níveis - a atualização e com o preparo para esse novo mundo do trabalho. Torna-se determinante que através da educação, a fim de garantir um de seus princípios e arcabouços, as condições de compreender e de se colocar na sociedade contemporânea, enquanto cidadãos incluídos, partícipes e responsáveis.

A globalização, então, permitiu o estreitamento das relações entre a academia e o mercado de trabalho, possibilitando o surgimento de várias metodologias que permitissem a mudança do foco da educação na formação integral dos estudantes na graduação, tornando-os protagonistas de sua própria aprendizagem empreendedora.

Utilizando métodos de vivência, quando o estudante é quem desenvolve sua formação completa, nas perspectivas do empreendedorismo e dentro de uma experiência prática, buscamos identificar em dois momentos distintos o sentimento deste estudante mediante as tarefas e atividades propostas pelo professor no desenvolvimento de uma ideia de negócio e elaborando o Plano de Negócio.

O desenvolvimento deste estudo se deu a partir da realização de pesquisa (DOS-REIS; ALBUQUERQUE; AZEVEDO, 2017) que analisou a percepção dos alunos sobre uma aplicação a utilização do Ciclo de Aprendizagem Vivencial (CAV), discutindo seu papel ativo no processo ensino-aprendizagem mediante a aplicação do método.

Partindo da pesquisa realizada, este trabalho tem como objetivo realizar uma análise comparativa da percepção de alunos de empreendedorismo em relação à sua participação ativa no processo de ensino-aprendizagem mediante a utilização do Ciclo de Aprendizagem Vivencial enquanto método ativo de ensino.

Tendo em vista o objetivo delineado, o presente artigo apresenta os resultados de uma pesquisa descritiva, caracterizada como estudo de caso. O trabalho encontra-se distribuído da seguinte forma: seguido desta introdução, tem-se o referencial teórico, abordando a educação empreendedora e os métodos ativos. Em seguida, apresentam-se as características da metodologia de pesquisa do estudo. Por fim, tem-se dos resultados e discussão, seguidos das conclusões do artigo. 


\section{Referencial Teórico}

Existe uma necessidade latente de aproximação entre abismo existente entre o mercado e academia. Alguns autores argumentam que nunca deveria ter ocorrido tal abismo e outros afirmam que a globalização trouxe um encurtamento de uma relação que sempre existiu. No Brasil, as Instituições de Ensino Superior (IES), principalmente as particulares, vêm sendo cobradas pelos seus alunos no sentido de diminuir esse gap. Ademais, o Ministério da Educação, por intermédio das Diretrizes Curriculares Nacionais deixa explícita essa necessidade de aproximação.

A educação tem foco no desenvolvimento de todas as atividades humanas, além de outros saberes, mais que conceitos, teoria e fundamentos, ou algoritmos, mais que aprender métodos e técnicas baseadas na teoria acadêmico-científica. Temos então os agentes, objetos e objetivos da educação que "normalmente" presenciamos nos papéis de Professor e Estudante.

Considerando todas as mudanças ocorridas no mundo desde que a educação se tornou a forma mais eficaz, efetiva e eficiente de transmissão de conhecimentos e sua evolução até chegarmos ao nosso século, modificando os aspectos de comunicação, métodos e técnicas, estes agentes, objetos e objetivos também se modificaram nos levando para uma nova perspectiva do ensino-aprendizagem.

São novas perspectivas da educação, baseadas nas novas tecnologia da comunicação e informação que nos levam a considerar que a formação então deve ser completa, mais especialmente “ ... em termos de desenvolvimento de habilidades cognitivas [...]" (LIBÂNEO, 1998, p. 8). Nesse contexto, por volta dos anos 2000, surge então o termo "educação empreendedora".

\section{Educação Empreendedora}

A aprendizagem empreendedora se dá pelo conhecimento, comportamento e aprendizagem afetivo-emocional, onde ocorre um processo de transformação de experiência e conhecimento em resultados (HEINOEN e AKOLA, 2007). Fowler (2010), ainda sobre este mesmo assunto, esclarece que Educação Empreendedora advém dos termos, em inglês, Entrepreneurship Education e Enterprise Education. O primeiro termo relacionado aos programas americanos visando a criação de negócios, e o segundo termo para o na perspectiva de desenvolver as características empreendedoras do indivíduo.

A Educação empreendedora pode abranger vários enfoques, momentos e objetivos. Como ressalta Lopes (2010):

Pode se perceber que a educação empreendedora pode enfocar a formação do indivíduo ou focar naquele que se interessa por uma oportunidade e que estaria numa fase anterior à criação de um negócio; pode, ainda, voltar-se para os que já estariam na fase de criação de um empreendimento e, até mesmo, para aqueles que estão em fases posteriores à criação e que estão preocupados com as estratégias para permanecer ativo ou expandir o negócio (LOPES, 2010, p. 25).

A Educação Empreendedora permitirá aos agentes, objeto e objetivo do processo transformador do indivíduo no desenvolvimento de comportamento empreendedores. Alinhado a esse olhar, o Serviço Brasileiro de Apoio às Micro e Pequenas empresas (SEBRAE), na busca de metodologias ativas que levassem a essa nova perspectiva de aprendizagem, desenvolveu e propôs um modelo, indo de encontro aos quatro pilares da 
educação da UNESCO que “... ressignifica (...), de forma a considerar os seguintes fundamentos: a autonomia para aprender, o desenvolvimento de atributos $e$ atitudes essenciais, buscando incentivar a competência na gerência de sua vida (pessoal, profissional e social)" (LOPES, 2016, p. 8).

Portanto, para chegar a esse ideal, a educação empreendedora exigirá dos professores uma postura muito mais de educador, mediador e colaborador. Mais que inovar, assumir os riscos das aplicações modificadoras, exige mudança de atitude e acima de tudo transformar hábitos, cuidar do planejamento e dos riscos de inovar.

O educador empreendedor precisa aprender a trabalhar as atitudes dos estudantes, incentivando-os a descobrirem seus talentos e senso de responsabilidade social. Além disso, deve fazer da sala de aula um ambiente que proporciona uma troca de conhecimentos e incentivo ao potencial de cada um, sendo assim esta a proposta quando o objeto e o objetivo da aprendizagem se juntam em uma perspectiva diferenciada de aprendizagem que é a metodologia ativa.

\section{Metodologias Ativas}

As metodologias ativas foram desenvolvidas em contraposição aos ensinos tecnicista e liberal das décadas de 1960 a 1980 no Brasil, e desenvolvida na abertura política com o final da ditadura militar quando surgiram os métodos de ensino baseado em uma pedagogia críticosocial dos conteúdos, que tinham como preocupação não só a formação para o trabalho, mas também a formação completa dos indivíduos.

Surge então o ensino sob novas perspectivas. Uma delas é a responsabilização do estudante, e outra onde o papel mais importante do professor é o de mediador e a formação do estudante tem que abranger aspectos como saber ser e saber fazer, ou seja, o desenvolvimento de conhecimento, habilidades e atitudes no meio acadêmico-escolar.

Há que se considerar aspectos como o uso das novas tecnologias da comunicação e da informação e o novo estilo de aprendizagem. Nesse cenário, as metodologias ativas são voltadas, segundo Souza, Iglesias e Pazin-Filho (2014), para a andragogia, onde se percebem algumas diferenças de aplicações métodos e técnicas tradicionais. A andragogia, segundo esses autores: i) percebe a diferença no aprendizado de adultos, buscando identificar seu perfil para fundamentar a aplicação da técnica adequada; ii) permite o uso de inúmeros métodos disponíveis, que variam em objetivo, complexidade e custo; iii) permite acompanhamento individualizado do progresso dos estudantes pois possibilitam o trabalho individual ou grupo; e iv) leva o professor a exercer papéis ativo e interativo no processo de aprendizagem.

\section{Ciclo de Aprendizagem Vivencial - CAV}

Trata-se de metodologia ativa utilizada pelo SEBRAE em sua disciplina de Empreendedorismo, e baseia-se em 5 fases bem definidas: Vivência, Relato, Processamento, Generalização e Aplicação (LOPES, 2016). Baseada na Teoria do Ciclo de Aprendizagem Vivencial de Kolb, o CAV tem como como orientação o trabalho em grupo:

(...) o papel principal desloca-se para o educando, que passa a ser o centro do processo, diferentemente do ensino. Isto facilita um envolvimento maior na busca de aprendizagem competitiva e cooperativa. $\mathrm{O}$ trabalho em grupo prevalece sobre a apresentação expositiva e individual do instrutor. O processo é calcado nos motivos dos estudantes, em um ambiente que desafia, ao mesmo tempo em que acolhe, 
combinando momentos de disputa e de união entre os estudantes e entre eles e o educador (OLIVEIRA e SUAIA, 2011, p. 10)

O CAV pode ser entendido como um sistema, onde recursos humanos ou não são inseridos, através de um processo de transformação (atividade), ocorrendo análises dos resultados alcançados (outputs) e fazendo comparativos com os ambientes que pertencem para melhorar suas práticas (feedbacks). Esse é um processo cíclico que vai se aperfeiçoando a cada atividade (retroalimentação).

Saber como estes estudantes sentem, presenciam e aprendem dentro dessa metodologia é o foco da pesquisa aqui apresentada, e a seguir apresentaremos o método de pesquisa utilizado para esse fim.

\section{Método}

Pesquisas descritivas expõem traços de determinada população ou fenômeno sem o compromisso de explicar os fenômenos. Normalmente tem como base grandes amostras, formatadas como levantamento ou survey (VIEIRA, 2002). O estudo de caso, por sua vez, de acordo com Yin (1989, p. 23) "é uma inquirição empírica que investiga um fenômeno contemporâneo dentro de um contexto da vida real, quando a fronteira entre o fenômeno e o contexto não é claramente evidente e onde múltiplas fontes de evidência são utilizadas".

Foi utilizado como instrumento de coleta de dados o questionário; trata-se de reaplicação de instrumento já utilizado, cujos resultados foram descritos em Reis, Albuquerque e Azevedo (2017) com vistas a realização de estudo comparativo, a fim de manter o mesmo grau de entendimento e resposta dos alunos, bem como as mesmas variáveis utilizadas no estudo, tabela 1.

\section{Tabela 1: Variáveis da percepção dos alunos em relação à disciplina}

\begin{tabular}{l|l}
\hline Variável & Descrição \\
\hline Nota_Disciplina2 & Nota de 01-10 atribuída a disciplina de Empreendedorismo \\
\hline Nota_Conteúdo2 & Nota de 01-10 atribuída ao conteúdo da disciplina de Empreendedorismo \\
\hline Como_se_Sentiu2 & Como se sentiu fazendo a disciplina de empreendedorismo \\
\hline Dific_Enfr2 & Maior dificuldade enfrentada na disciplina \\
\hline Aprendizado2 & O que ficou de aprendizado \\
\hline
\end{tabular}


Sugest_Melhoria2

Sugestões para melhoria para o formato disciplina

Fonte: Elaborado pelos autores.

Os dados foram coletados via formulário eletrônico no período entre junho/julho de 2017 quando os alunos tiveram a possibilidade de acessar o link e responder ao questionário semi-aberto contendo duas questões de múltipla escolha referente à avaliação da disciplina e do conteúdo visto durante o semestre, e seis questões de livre resposta referentes às dificuldades enfrentadas, como o aluno se sentiu no decorrer da disciplina, o que ficou de aprendizado, a contribuição da disciplina de empreendedorismo em outras matérias do curso, recomendações aos novos alunos e sugestões de melhoria, garantindo os preceitos de confidencialidade e tratamento agrupado dos dados. Participaram do estudo 41 estudantes.

Foi utilizada a abordagem quantitativa com análise a partir de estatística descritiva para tratamento das questões de múltipla escolha enquanto que para o tratamento das respostas referente às perguntas abertas foi utilizado o software IRAMUTEC a partir das técnicas qualitativas de frequência de formas ativas de palavras, até a $25^{\text {a }}$ posição, e a classificação hierárquica descendente (CHD).

Para o tratamento dos resultados foi utilizada a técnica de comparação a fim de perceber semelhanças e diferenças, regularidades ou deslocamentos da percepção dos alunos em relação à pesquisa realizada no trabalho de Dos-Reis, Pacheco, Azevedo (2017) tomado como base para o desenvolvimento deste artigo.

Os resultados obtidos a partir da análise dos dados coletados bem como da comparação realizada entre os trabalhos serão descritos e discutidos na seção a seguir.

\section{Resultados e discussão}

Este artigo foi desenvolvido com o propósito de realizar uma análise comparativa dos resultados de pesquisa referente à percepção do aluno de empreendedorismo em relação à sua participação ativa no processo de ensino-aprendizagem mediante a utilização do Ciclo de Aprendizagem Vivencial enquanto método ativo de ensino. Neste sentido, serão demonstrados primeiramente os resultados do quadro de frequência de formas ativas de palavras e em seguida a classificação hierárquica descendente (CHD) o que corresponde à etapa qualitativa deste trabalho.

Frequência de formas ativas de palavras e análise comparativa entre os resultados dos artigos

O quadro de frequência de formas ativas, quadro 1, traz uma compilação dos resultados de análise realiza em cada uma das variáveis referentes a como o aluno se sentiu durante o semestre na disciplina de empreendedorismo, as dificuldades enfrentadas, 0 aprendizado e as sugestões de melhorias.

\section{Quadro 1: Variáveis da percepção dos alunos em relação à disciplina}




\begin{tabular}{|c|c|c|c|c|c|c|c|c|}
\hline & \multicolumn{2}{|c|}{ Como se sentiu } & \multicolumn{2}{|c|}{$\begin{array}{l}\text { Dificuldades } \\
\text { Enfrentadas }\end{array}$} & \multicolumn{2}{|c|}{ Aprendizado } & \multicolumn{2}{|c|}{$\begin{array}{l}\text { Sugestão de } \\
\text { Melhoria }\end{array}$} \\
\hline Num & Forma & Freq & Forma & Freq & Forma & Freq & Forma & Freq \\
\hline 1 & sentir & 7 & Plano & 7 & Negócio & 4 & estar & 7 \\
\hline 2 & satisfeito & 5 & Negócio & 7 & empreender & 4 & disciplina & 5 \\
\hline 3 & empreendedor & 4 & Não & 4 & Coisa & 4 & bom & 5 \\
\hline 4 & trabalho & 3 & Dificuldade & 4 & Prático & 3 & melhorar & 4 \\
\hline 5 & empresa & 3 & Disciplina & 4 & fundamental & 3 & ótimo & 3 \\
\hline 6 & empreender & 3 & Muito & 3 & Ficar & 3 & ver & 3 \\
\hline 7 & disciplina & 3 & Desenvolver & 3 & Dar & 3 & professor & 3 \\
\hline 8 & bom & 3 & Falar & 3 & Aprender & 3 & melhor & 3 \\
\hline 9 & abrir & 3 & Falta & 3 & Só & 2 & ficar & 3 \\
\hline 10 & tranquilo & 2 & Ficar & 3 & Próprio & 2 & aula & 3 \\
\hline 11 & professor & 2 & Montar & 3 & Problema & 2 & atividade & 3 \\
\hline 12 & privilegiado & 2 & Negociar & 3 & planejamento & 2 & achar & 3 \\
\hline 13 & possível & 2 & Trabalho & 3 & organização & 2 & sugerir & 2 \\
\hline 14 & perceber & 2 & Aula & 2 & negociar & 2 & projeto & 2 \\
\hline 15 & importante & 2 & Começo & 2 & montar & 2 & plano & 2 \\
\hline
\end{tabular}




\begin{tabular}{|l|l|l|l|l|l|l|l|l|}
16 & ideia & 2 & Criatividade & 2 & melhor & 2 & pesquisa & 2 \\
\hline 17 & grande & 2 & Dar & 2 & inovar & 2 & negócio & 2 \\
\hline 18 & gostar & 2 & Estudar & 2 & importância & 2 & maior & 2 \\
\hline 19 & aprender & 2 & Frente & 2 & ideia & 2 & jeito & 2 \\
\hline 20 & ótimo & 1 & Grupo & 2 & estudar & 2 & estragar & 2 \\
\hline
\end{tabular}

Quadro 1. Frequência de formas ativas de palavras do discurso produzido.

Fonte: Elaborado pelos autores.

Os resultados da análise apresentam as palavras que mais se destacaram nas respostas dos alunos. A justificativa destes resultados podem ser observados a partir da fala dos próprios alunos. Estas falas podem ser comparadas com a resposta dos alunos em relação a cada um dos itens perguntados na pesquisa anterior.

No que se refere a como o aluno se sentiu durante a realização da disciplina as palavras com maior ocorrência foram "sentir", "satisfeito" e "empreendedor". Este resultado leva ao entendimento de que os discentes sentiram-se satisfeitos de forma geral em relação à sua participação na disciplina de empreendedorismo, o que os proporcionou a sensação de sentirem-se verdadeiros empreendedores.

Este resultado pode ser observado a partir da fala dos alunos tanto no que se refere aos dados atuais quanto no que tange aos dados analisados no trabalho anteriormente realizado conforme segue:

Quadro 02: Sentimento do aluno em relação à sua participação na disciplina.

\begin{tabular}{|c|c|}
\hline Dos-Reis; Albuquerque; Azevedo, Pequeno ( 2017) & Dos-Reis; Albuquerque; Azevedo ( 2017) \\
\hline $\begin{array}{r}\text { "Muito satisfeita”(Aluno 6) } \\
\text { “Um empreendedor lá fora” (Aluno 11) } \\
\text { "Muita satisfação. Desenvolvemos grandes } \\
\text { trabalhos e não poderia estar mais satisfeito." } \\
\text { (Aluno 12) } \\
\text { "me senti privilegiado em estudar essa matéria, ter } \\
\text { boas noções de como ser um empreendedor" } \\
\text { (Aluno 21) } \\
\text { "Um empreendedor" (Aluno 34) } \\
\text { "Um empreendedor" (Aluno 37 }\end{array}$ & $\begin{array}{r}\text { "Um empreendedor" (Aluno 04) } \\
\text { "Uma empreendedora" (Aluno 08) } \\
\text { "Satisfeito pois descobri como ser um } \\
\text { empreendedor" (Aluno 20) } \\
\text { "Um empreendedor, da vontade de já sair } \\
\text { mudando o mundo" (Aluno 22) } \\
\text { "Um estudante mais atualizado no mundo } \\
\text { empreendedor" (Aluno 39) } \\
\text { “Feliz e motivada a ser uma boa gestora e } \\
\text { empreendedora" (Aluno 47) } \\
\text { "Bem, como se já tivesse sido um } \\
\text { empreendedor" (Aluno 77) } \\
\text { "Meu dom empreendedor aflorou” (Aluno 131) }\end{array}$ \\
\hline
\end{tabular}


Fonte: Elaborado pelos autores.

Além das formas mais citadas, outras palavras importantes também surgiram como "empreender", "tranquilo", "bom”, "possível”, "importante", "ótimo", "grande", "superar", "aprender". Estas são palavras relacionam-se a um fator positivo no que se refere à percepção dos alunos em relação à disciplina de empreendedorismo, a credibilidade no conhecimento que adquiriram durante a disciplina.

Apesar dos resultados positivos da percepção dos alunos em relação à sua participação na disciplina de empreendedorismo, pode-se observar também a ocorrência de dificuldades enfrentadas principalmente no que diz respeito ao desenvolvimento de um plano de negócios.

As palavras mais freqüentes para esta variável foram "plano", "negócio", "não", "dificuldade" e "disciplina". Isto mostra que apesar do espírito empreendedor ser um fator aparente, os alunos apresentaram certa dificuldade com o fator técnico que é, neste caso, a elaboração de um plano de negócios. O comportamento empreendedor envolve características como persistência, criatividade, visão de futuro dentre outras que estão relacionadas à personalidade, porém, é necessário que todo empreendedor busque capacitação profissional e técnica no que diz respeito, por exemplo, a planejamento, organização, controle e gestão. A seguir, trechos com respostas dos alunos:

Quadro 03: Dificuldades enfrentadas pelos alunos.

\begin{tabular}{|c|c|}
\hline $\begin{array}{l}\text { Dos-Reis; Albuquerque; Azevedo, Pequeno ( } \\
\text { 2017) }\end{array}$ & Dos-Reis; Albuquerque; Azevedo ( 2017) \\
\hline $\begin{array}{r}\text { “Fazer um plano de negócio” (Aluno 2) } \\
\text { “Montar o plano de negócios" (Aluno 3) } \\
\text { "De desenvolver o Negócio e saber ser } \\
\text { inovador." (Aluno 4) } \\
\text { "Plano de negócio e canvas" (Aluno 5) } \\
\text { "Plano de negocio" (Aluno 8) } \\
\text { “Fazer o quadro do plano de negocio" (Aluno } \\
9 \text { ) } \\
\text { “no começo foi o plano de negócios para abrir } \\
\text { a empresa," (Aluno 21) } \\
\text { "Montar nosso plano de negocio" (Aluno 22) }\end{array}$ & $\begin{array}{r}\text { “Quadro e plano de negócios" (Aluno 10) } \\
\text { "O quadro de modelo de negócios" (Aluno } \\
\text { "Quadro de modelo de negócios" (Aluno 13) } \\
\text { "Quadro de negócios" (Aluno 16) } \\
\text { "O conteúdo de montar o plano financeiro, } \\
\text { quadro de modelo de negócios" (Aluno 22) } \\
\text { “A complexidade do plano de negócios" } \\
\text { (Aluno 29) } \\
\text { "Formular um plano de negócios" (Aluno 30) } \\
\text { "Me adequar ao quadro de negócios" (Aluno }\end{array}$ \\
\hline
\end{tabular}

Tendo em vista que a disciplina de empreendedorismo se desenvolve dentro de um período médio de cinco meses e que divide-se entre conteúdo teórico e atividades práticas, o curto período de tempo para a construção do plano de negócio pode dificultar nos alunos o desenvolvimento da capacidade de elaboração deste elemento técnico.

Quando comparamos os resultados deste trabalho com os resultados de Dos-Reis; Albuquerque; Azevedo (2017), podemos notar que o problema permanece no que se refere ao desenvolvimento dos elementos técnicos "plano de negócio" e "quadro de modelo de negócio". Alguns alunos informaram que:

“O tempo que tivemos não colaborou muito.” (Aluno 29) 
“O tempo que era corrido e não dava pra pesquisar muito" (Aluno 37)

"Tempo não tenho" (Aluno 38)

Apesar das dificuldades enfrentadas em relação ao tempo e assimilação dos aspectos técnicos para elaboração do plano de negócios, quando perguntados sobre o que ficou de aprendizado os alunos demonstraram o reconhecimento da importância tanto do desenvolvimento de características empreendedoras como da capacitação técnica. Algumas palavras que surgiram a partir da análise dos dados e que reforçam esta afirmativa são "planejamento", "organização", "estudar". As palavras mais freqüentes desta etapa de análise foram "negócio", "empreender" e "coisa".

Quadro 04: O que ficou de aprendizado.

\begin{tabular}{|c|c|}
\hline Dos-Reis; Albuquerque; Azevedo, Pequeno ( 2017) & Dos-Reis; Albuquerque; Azevedo ( 2017) \\
\hline $\begin{array}{r}\text { "Fica o aprendizado. Hoje eu sei o que é } \\
\text { empreender e tenho total segurança pra abrir meu } \\
\text { próprio negócio." (Aluno 6) } \\
\text { “Muita coisa legal , inclusive como montar meu } \\
\text { próprio negócio”(Aluno 9) } \\
\text { “Fica o aprendizado. Hoje me sinto pronta pra } \\
\text { abrir meu próprio negócio.” (Aluno 18) } \\
\text { "A. Técnica do Canvas é de fundamental } \\
\text { importância para se iniciar um negócio”(Aluno } \\
\text { "Muita coisa, principalmente a vontade de tero } \\
\text { meu negocio.”(Aluno 23) } \\
\text { “A importância de compreender os riscos de um } \\
\text { negócio."(Aluno 36) }\end{array}$ & 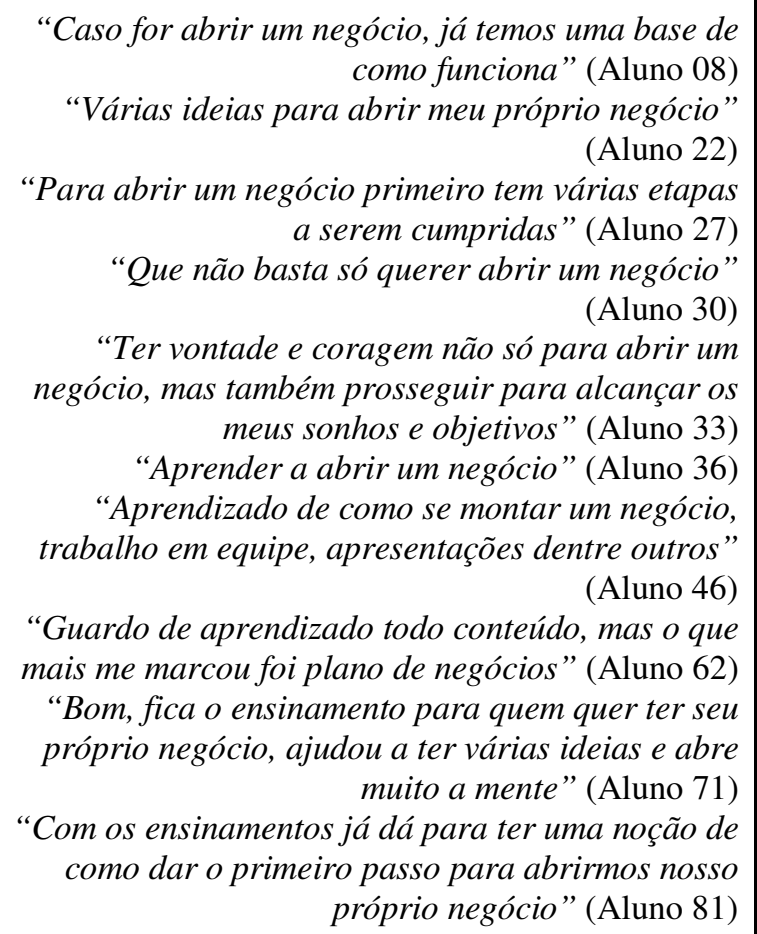 \\
\hline
\end{tabular}

Fonte: Elaborado pelos autores.

As observações dos alunos reforçam que apesar das dificuldades existentes no processo de ensino-aprendizagem é real a possibilidade de atingir os objetivos do ensino. No caso da disciplina de empreendedorismo tanto os fatores relacionados ao desenvolvimento das características empreendedoras quanto à capacitação técnica. Vale ressaltar que a dificuldade demonstrada pelos alunos em desenvolver o instrumento técnico que é o plano de negócios, 
não anulou a percepção sobre a importância desta capacitação. O objetivo geral da disciplina de empreendedorismo presente no plano de ensino desta disciplina versa que:

"Ao término da disciplina de empreendedorismo o aluno deverá ter conhecimento dos atributos essenciais que proporcionam ao empreendedor o desenvolvimento da capacidade de autonomia para o aprendizado e a competência para o gerenciamento de sua vida pessoal, profissional e social."

Ou seja, a educação empreendedora não resume-se à capacitação técnica, ela não se limita às paredes da sala de aula e muito menos extingue-se com o encerramento do semestre. Educar alunos dentro de uma perspectiva do empreendedorismo trata-se de fazê-los despertar para suas potencialidades tanto no que diz respeito ao desenvolvimento de ferramentas de trabalho quanto no que se refere à superação de fragilidades e gestão de suas metas e objetivos.

$\mathrm{O}$ discursos dos alunos nos dois trabalhos comparados, em questão, reforçam a importância do desenvolvimento do espírito empreendedor, e é possível compreender, adicionalmente, que as dificuldades enfrentadas neste caminho, são inerentes ao processo da aprendizagem, porém, é válido ressaltar que mais importante não são as barreiras encontradas visto que o foco deve ser dado a solução tendo em vista o atendimento dos objetivos.

Expostos os resultados referentes ao sentimento dos alunos em relação a sua participação na disciplina de empreendedorismo, suas dificuldades e o que ficou de aprendizado, passamos agora para a análise a respeito de quais sugestões de melhores estes alunos indicaram a fim de que a disciplina de empreendedorismo possa melhorar a cada novo semestre.

As palavras que obtiveram as maiores freqüências foram "estar", "disciplina", "bom" e "melhorar". A seguir, pode-se observar o posicionamento dos alunos em relação a esta questão:

Quadro 05: Recomendações de melhoria

\begin{tabular}{|c|c|}
\hline Dos-Reis; Albuquerque; Azevedo, Pequeno ( 2017) & Dos-Reis; Albuquerque; Azevedo ( 2017) \\
\hline $\begin{array}{r}\text { “Do jeito que tá está muito bom, ótimo" (Aluno 3) } \\
\text { "Na minha concepção a disciplina está ótima." } \\
\text { (Aluno 5) } \\
\text { “se melhorar mais, estraga" (Aluno 18) } \\
\text { "Gostei de tudo disciplina professor"(Aluno 26) } \\
\text { "Não tem o que melhorar" (Aluno 31) } \\
\text { "Pra mim foi muito bom a experiência com a } \\
\text { disciplina" (Aluno 36) }\end{array}$ & 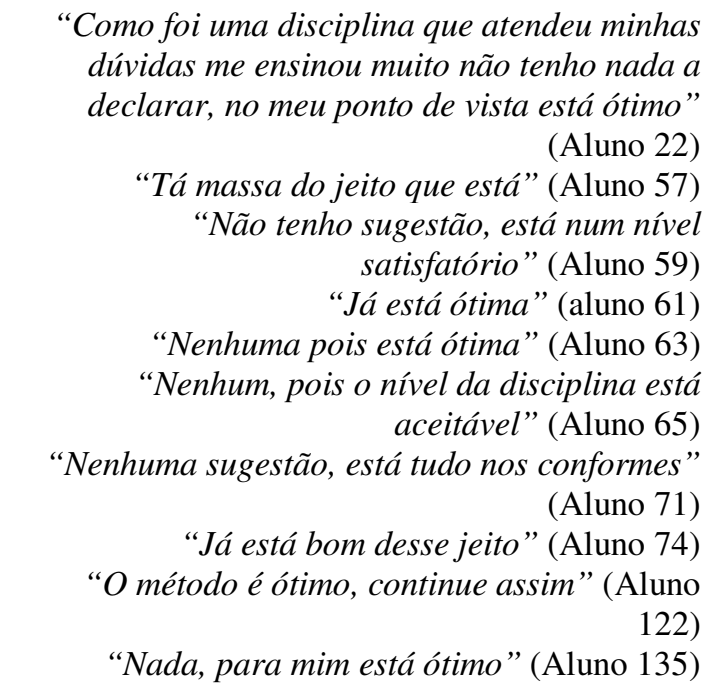 \\
\hline
\end{tabular}


Houve uma prevalência de comentários relacionados ao elogio da disciplina como pode ser observado em relação às palavras mais citadas nas respostas em ambos os trabalhos, porém, sugestões de melhoria também surgiram, como por exemplo: "Aumentar um pouco o tempo pra montar o plano de negócio"; "na minha opinião ainda mais aulas praticas", "Ter mais aulas práticas", "maior carga horária”. Com isto, confirma-se o posicionamento dos alunos em relação à dificuldade de elaboração do plano de negócios em função do tempo despendido para o desenvolvimento desta ferramenta. A sugestão por mais aulas práticas e tempo maior para desenvolvimento na aprendizagem desta ferramenta é um fator a ser considerado.

Este resultado é fortalecido quando observamos as notas atribuídas pelos alunos no que se refere à avaliação da disciplina de empreendedorismo, bem como em relação ao conteúdo visto durante o semestre. Estes dados quantitativos podem ser observados nos gráficos a seguir:

Gráfico 01: Notas de avaliação atribuídas pelos alunos à disciplina de empreendedorismo
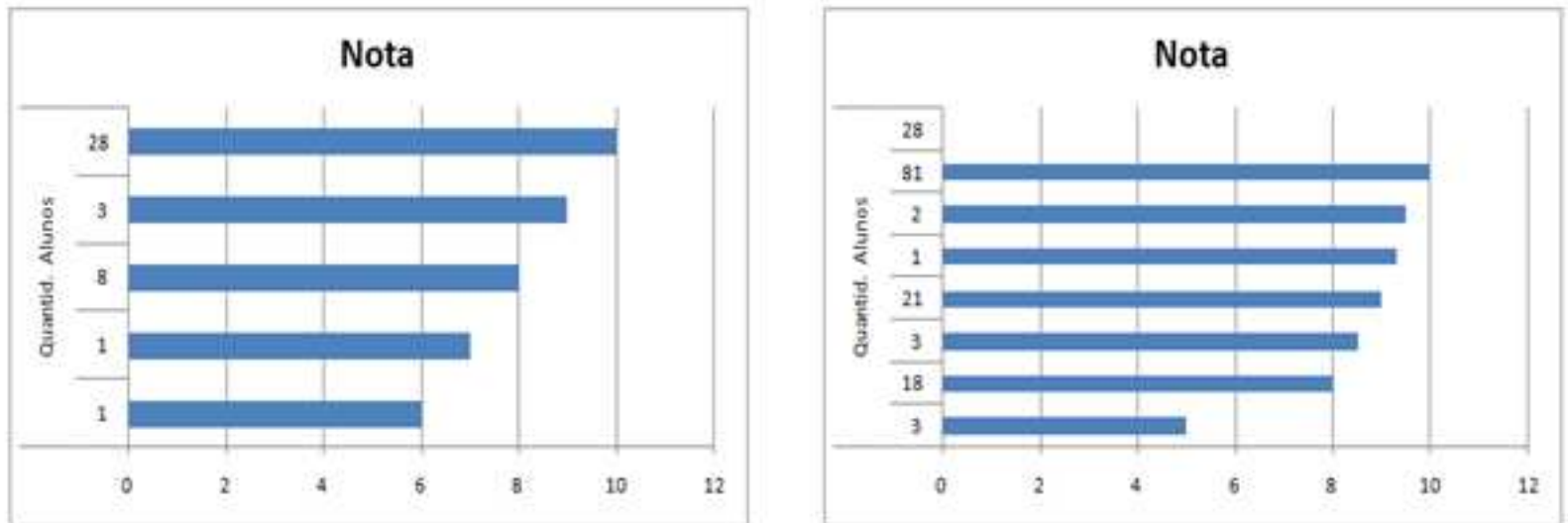

Gráfico 02: Notas de avaliação do conteúdo visto na disciplina de empreendedorismo 

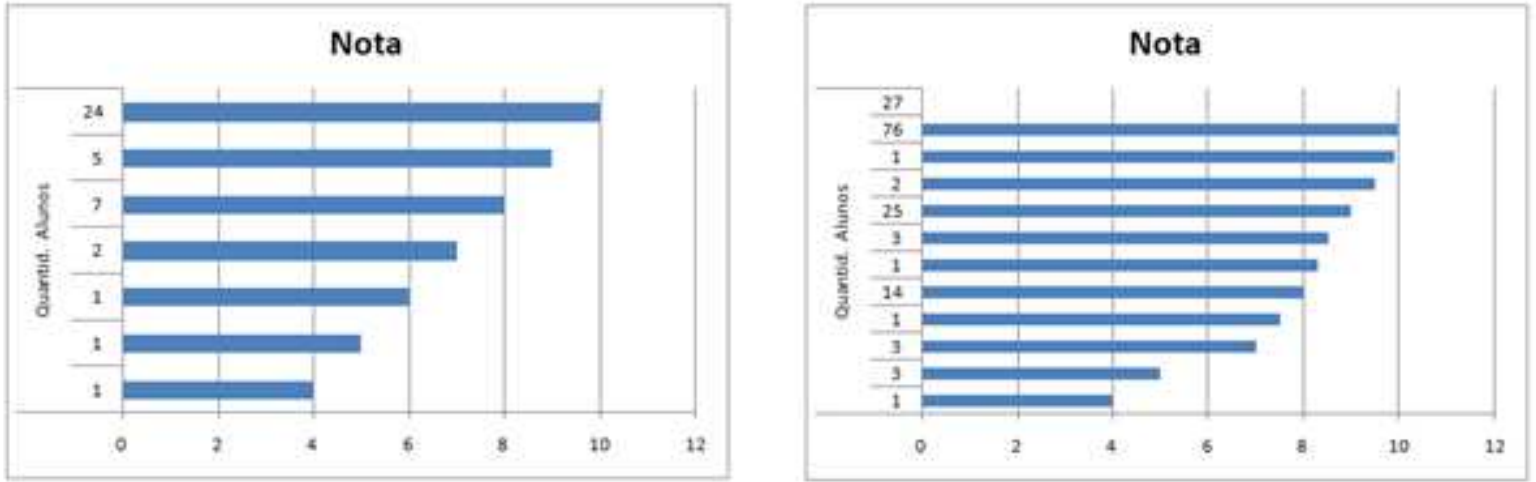

\section{Conclusão}

Mudar a própria vida ao desenvolver o potencial profissional na atualidade é papel da educação, envolve todo tipo de aprendizagens, bem como métodos e técnicas tradicionais e inovadoras como são as metodologias ativas e a aplicação do Ciclo de Aprendizagem Vivencial de Kolb é hoje a percepção dos estudantes dos cursos de administração e de gestão em várias instituições de ensino superior do país.

Para a disciplina de empreendedorismo, que, como apontamos neste artigo recebe atenção especial no sentido de estabelecer adequadamente metodologias que privilegiem a ação e a nova posição de estudante e professor mediante o pensar um negócio e desenvolver um plano estratégico, buscamos saber como este estudante percebe a aplicação dos métodos, o uso do tempo, a responsabilização com as atividades propostas, os desafios lançados pelo professor.

Esta experiência mostra que os estudantes gostam de assumir o papel que lhe compete de protagonistas, bem como o desenvolvimento de outras capacidades e habilidades individuais e coletivas como criatividades, responsabilidade, relacionamento interpessoal, pois apresentam muito mais do que o Plano de Negócio detalhado e complexo, como também o piloto de cada um dos negócios propostos.

\section{Referências Bibliográficas}

DELORS, J. (Org). Os Quatro Pilares da Educação. In: EDUCAÇÃO UM TESOURO A DESCOBRIR: Relatório para a UNESCO da Comissão Internacional sobre Educação para o século XXI. São Paulo: Cortez; Brasília, DF: MEC: UNESCO, 1998. Cap. 4, p. 89-102.

FILION, L. J. EMPREENDEDORISMO E GERENCIAMENTO: processos distintos, porém complementares. RAE - Revista de Administração de Empresas / EAESP / FGV, São Paulo, Brasil.. RAE Light v. 7 n. 3 p. 2-7 Jul./Set. 2000

FOWLER, F. R. UNIFEI - Universidade Federal de Itajubá: Uma universidade empreendedora. In: LOPES, Rose M(org.) Educação Empreendedora: conceitos, métodos e práticas. Rio de Janeiro: Elsevier; São Paulo: SEBRAE, 2010.

HEINONEN, J., AKOLA, E. (2007), Entrepreneurship Training and Entrepreneurial Learning in Europe - Results from the ENTLEARN Project, TSE Entre, Turku School of Economics, Esa Print Oy, Tampere. 
LAVIERI, C. Educação... Empreendedora? In: EDUCAÇÃO EMPREENDEDORA : conceitos, modelos e práticas. Rio de Janeiro : Elsevier ; São Paulo : Sebrae, 2010.

LIBÂNEO, J. C. ADEUS PROFESSOR, ADEUS PROFESSORA: novas exigências educacionais e profissão docente. Cortez: São Paulo, 1998.

LIZUCA, E. S., \& MORAES, G. H. S. M. (2014). POTENCIAL E PERFIL EMPREENDEDOR DO ESTUDANTE DE ADMINISTRAÇÃO E O AMBIENTE UNIVERSITÁRIO: Investigação em três IES de São Paulo, Anais... XVII Semead, Seminários em Administração, São Paulo.

LOPES, M.P; OROFINO, M.A. DISCIPLINA DE EMPREENDEDORISMO: manual do professor. Brasília: SEBRAE, 2016

LOPES, R.M. A. Referenciais para a Educação empreendedora. In: LOPES, R.M. A. (Orga.). EDUCAÇÃO EMPREENDEDORA: conceitos, modelos e práticas. cap. 1. Rio de Janeiro: Elsevier; São Paulo: Sebrae, 2010.

OLIVEIRA, M. A.; SAUAIA, A. C. A. IMPRESSÃO DOCENTE PARA APRENDIZAGEM VIVENCIAL: um estudo dos benefícios dos jogos de empresas. Administração: Ensino e Pesquisa, [S.1.], v. 12, n. 3, p. 355-391, set. 2011. ISSN 2358-0917. Disponível em:

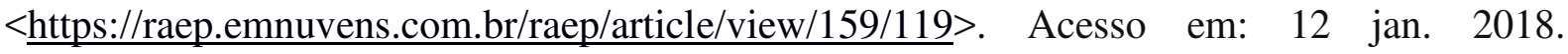
doi:https://doi.org/10.13058/raep.2011.v12n3.159.

DOS-REIS, M. C. A.; ALBUQUERQUE, V. P.; AZEVEDO, S. B. Métodos ativos de ensino: Caso de aplicação do Ciclo de Aprendizagem Vivencial (CAV) com estudantes de empreendedorismo da educação superior. Anais do X CASI - X Congresso de Administração, Sociedade e Inovação. Petrópolis(RJ) FMP-FASE, 2018 Disponivel em: $<$ www.even3.com.br/anais/xcasi $>$ Acesso em mar. 2018.

SEBRAE Disponível em: http://www.sebrae.com.br/sites/PortalSebrae/sebraeaz/educacaoempreendedora-no-ensino-superior,46811406bad46410VgnVCM1000003b74010aRCRD

Acesso em 10 de fev. 2018

SOUZA C.S., IGLESIAS A.G., PAZIN-FILHO A. Estratégias inovadoras para métodos de ensino tradicionais - aspectos gerais. Revista da Faculdade de Medicina de Ribeirão Preto e do Hospital das Clínicas da FMRP Universidade de São Paulo. N 47(3), cap VI, pgs:284-292, 2014. Disponível em file://C:/Users/78430860134/Documents/86617-122264-1-SM.pdf Acesso em fev. 2018

VIEIRA, S. F. A.; MELATTI, G. A.; OGUIDO, W. S.; PELISSON, C.; NEGREIROS, L. F. ENSINO DE EMPREENDEDORISMO EM CURSOS DE ADMINISTRAÇÃO: um levantamento da realidade brasileira. Revista de Administração FACES Journal, v. 12, n. 2, p. 93-114, 2013.

VIEIRA, V. A. As tipologias, variações e características da pesquisa de marketing. Revista da FAE, v. 5, n. 1, 2002. Disponível em file:///C:/Users/78430860134/Documents/449-11801-SM.pdf Acesso em fev.2018

YIN, Robert K. - Case Study Research - Design and Methods. Sage Publications Inc., USA, 1989.

ZDEPSKI, F. B. Treinamento experiencial como método de ensino. In: Congresso Nacional de Educação - EDUCERE: Formação de Professores - Edição Internacional, 8, Curitiba. Anais. Curitiba: Pontifícia Universidade Católica do Paraná, 2008, v. 8, p. 11197-11209. 
